\title{
Improving the Efficiency and Effectiveness of Risk-Based Internal Audit Engagements
}

\author{
Philna Coetzee ${ }^{1}$ and Dave Lubbe ${ }^{2}$ \\ ${ }^{1}$ University of Pretoria \\ ${ }^{2}$ University of the Free State
}

The role of internal auditing in assisting with the mitigation of key risks threatening organisations has increased, not least, for example, in ensuring that engagements are performed more effectively and efficiently, and that all the key risks of organisations are addressed, but also to ensure that scarce internal audit resources are used optimally. This article describes the development of a model that can be used by internal auditors to perform this task. The model was developed from a study of the academic literature, current business practice norms, and other documentation whereafter it was tested in a practical scenario, and input from heads of internal audit departments in prominent South African organisations was obtained. The findings of the study, inter alia, support the use of the model. However, a concern is that the risk management strategy currently implemented by organisations is not mature enough for internal auditing to rely on the outcome of the risk management process, a prerequisite for the model to function optimally. A second concern is that internal auditing is reluctant to use a pure risk-based approach when performing audit engagements and still prefers to use a control-based approach with more emphasis placed on high risk areas.

Key words: Internal auditing, engagement planning, risk management process, internal audit engagement process, risk-based internal audit engagements, views of chief risk officers, audit more effective and efficient

\section{INTRODUCTION}

Risk and the management thereof is not a new concept. In recent years, risk taking and its management has taken on a new dimension. One such example is the risks taken which resulted in the current global financial crisis. The global financial crisis was in many ways a shock to the business world, the biggest problem being that it was not foreseen by economists, and relevant stakeholders, organisations and governments were caught unprepared. In May 2007 the Organisation for Economic Co-operation and Development made the following statement: 'the current economic situation is in many ways better than what we have experienced in years. Our central forecast remains indeed quite benign' (cited in Keen, 2008). Three months later this statement was contradicted as markets in the United States of America went into decline: house prices fell and organisations went into serious financial crisis. This was rapidly followed by the rest of the world's financial markets and other organisations that ran into financial difficulties (Keen, 2008). Many argued that the core of this crisis was the lack of an effective and efficient risk management strategy (Lam, 2009: 23; Hull, 2009: 3), and the question was asked: Where were the auditors? referring to both internal and external auditors (Mathker, 2008; Olah, 2009: 11; Lubbe, 2009).

The types of risks that initiated the global financial crisis are typically only discovered by a sound risk management strategy, something that the board are responsible for (IOD, 2009: 73-76), but that internal auditors need to ensure is functioning efficiently and effectively (IOD, 2009: 80; IIA, 2012: 2120); and, if so, incorporate the investigation of the mitigation of the key risks threatening the organisation into their activities. At the same time, the evolution of corporate governance has forced management to revisit the roles and

Correspondence to: Philna Coetzee, Professor in Auditing, Department of Auditing, University of Pretoria, South Africa. Email: philna. coetzee@up.ac.za responsibilities of various parties (Gramling et al., 2004: 195; Gendron, Cooper \& Townley, 2007: 105), arguably the most important being the internal audit function. Furthermore, the internal audit profession has realised that it will have to adapt to the changing environment in which it operates, an idea supported by a study performed by PricewaterhouseCoopers (2008), which concluded that it is essential for the profession to adopt new mindsets if it wants to retain a key role in the future.

Risk management and internal auditing have a connection, as can be seen from the above discussion, and this has been substantiated by many recent studies and surveys. However, most of these, although referring to risk-based internal auditing, reflect on the role that internal auditing should play with regard to the organisation's overall risk management strategy; with recommendations ranging from providing assurance on the soundness of the strategy to taking responsibility for its implementation. Furthermore, although some literature refers to the concept of risk-based internal auditing (Pelletier, 2008: 73; IOD, 2009: 94; Koutoupis \& Tsamis, 2009: 106; Castanheira, Rodrigues \& Craig, 2010: $83)$, this term focuses on the internal audit function's annual plan based on the strategic risks inherent in the plan. Both these scenarios ignore the potential benefits of using risk methodologies as the basis when performing internal audit engagements. Research papers supporting this tendency include a study of the internal audit methodologies of Greek banks (Koutoupis \& Tsamis, 2009: 102), which revealed that many internal audit functions, although using the term 'risk-based internal auditing', could not justify its use since any form of risk assessment or risk-based audit planning was conspicuously absent, thus undermining the term 'risk-based internal auditing' even further. This lack of risk-based internal audit engagement is also supported in a study by Castanheira et al. (2010: 95) where most participants indicated that they do perform risk-based planning for their annual internal audit plan, but that 
only one third incorporate risk into their engagement planning. Similarly, a study by Khanna (2011: 59) concluded that Indian banks have adopted a staggered approach to implementing risk-based internal auditing.

From the above discussion it seems that there is still a lack of understanding of what risk-based internal auditing entails for the performance of an audit engagement. The objective of this article is to provide a model that will improve the efficiency of internal audit engagements by incorporating risk methodologies more effectively into the engagement process. The model could be used by internal auditors to address all the key risks of the organisations, while simultaneously ensuring efficient use of their scarce resources (Fasset, 2011). The article will also assist in broadening the knowledge base of risk-based internal audit engagements as information seems to be limited. The Institute of Internal Auditors (IIA) would also benefit from this discussion, as it provides insight into the relative adequacy of its guidance to practitioners on performance of risk-based internal audit engagement.

The layout of the rest of the article is as follows: firstly, we present a short discussion of the various research methodologies followed, including the scope and limitations. Section 3 presents a discussion of the literature covering the risk-based internal audit engagement process. This is followed in Section 4 with a description of the model. A more comprehensive discussion on the research methodology is given in Section 5, together with the empirical findings gathered during the testing of the model. Conclusions are drawn and recommendations are made in Section 6.

\section{RESEARCH METHODOLOGY, SCOPE AND LIMITATIONS}

To address the research objective, various research methodologies were followed. Firstly, a comprehensive literature review was performed to get an understanding of what a modern risk-based internal audit engagement process should entail, and from that information, to develop a model. Secondly, the model was tested by means of a case study (see Section 5.1 for an explanation of the research methodology and findings) to ensure that the model was effective (all significant audit findings captured and reported on in a timely manner) and efficient (fewer audit procedures were performed, but with more intense focus on the areas of key risk). Thirdly, the views of heads of internal audit functions (hereafter referred to as chief audit executives, CAEs) within prominent risk-mature Top 40 private sector companies listed on the South African stock exchange (the JSE Limited), were obtained and analysed to determine the use of such a model in practice (see Section 5.2 for an explanation of the research methodology and findings).

A limitation of this article is that time and budget did not allow for all the available risk management frameworks to be used to exhaustively identify the incorporation of risk methodologies in the internal audit engagement process. However, the Committee of Sponsoring Organisations (COSO) has developed a well-recognised framework on risk management (2004) which was used as the basis for the research for this article. Also, the article only focuses on the planning stage of the internal audit engagement. However, if the planning phase is based on risk methodologies, the execution of the rest of the engagement will also be risk-based. A further limitation was that the company that was chosen to test the model was selected essentially for its willingness to participate. However, the authors believe that as it is one of the top five risk-mature companies of the Top 40 companies listed on the JSE Limited, which may negate any negative connotations of self-selection, and probably enhances the quality of the data gathered. Also, only South African companies were included in the study and only five companies were chosen to be included in the empirical study, based on their risk-maturity levels as determined by using the Risk and Insurance Management Society risk maturity model (RIMS, 2006). However, the fact that interviews were performed using a structured questionnaire, and that participating companies were chosen based on their high risk-maturity levels, enhances the quality of the data.

\section{LITERATURE REVIEW ON THE RISK-BASED INTERNAL AUDIT ENGAGEMENT PROCESS}

The literature review is presented in two parts: firstly, a discussion on the evolution of internal audit engagements and the inclusion of risks and risk methodologies, and secondly, a discussion of the literature covering the research and current practices with regard to risk-based internal audit engagements.

\subsection{Evolution of the internal audit engagement process}

The investigation into the evolution of the internal audit engagement revealed that internal auditing has been influenced over the last few decades by the changing business environment, and has undergone, and is still undergoing, a number of transformations. The literature (McNamee \& Selim, 1998: 5; Spira \& Page, 2003: 653-56; Hyde, 2007: 65-68) distinguishes between four generations, namely pre-1980, the 1980s, the 1990s, and 2000 and beyond, based on, inter alia, the types of activities performed, when activities are performed, what factors influence the planning of an engagement and how it is executed. The word 'risk' makes its appearance from the second generation, referring to financial and compliance risk only. It is only from the third generation (the 1990s) and onwards that 'risk' is more broadly incorporated into the engagement process. However, the question remains: How is the internal audit engagement process methodology linked to current risk methodologies and modern approaches to mitigate risks?

One of the most comprehensive frameworks on the risk management process is documented in the COSO Report (2004), providing guidance on what risk management entails, methodologies, terminologies, responsible parties, the steps in the risk management process, to name a few; thus focusing on risk management, and suggesting that internal control is one of the risk mitigating activities (a risk-driven approach). At first glance it seems that this framework is the basis for the fourth generation internal audit engagement process. The first COSO Report (1992), which is currently being updated (COSO, 2012), focuses on internal control with risk assessment being a step in the development and implementation of appropriate controls (a control-driven approach). It could thus be possible that the 1992 framework reflects on the third generation internal audit engagements. The third and fourth generation internal 
Table 1: Comparing the evolution of internal audit engagements with the COSO frameworks

Engagement planning elements

Starting point

Additional steps and/ or information during planning

Engagement procedures

Scope
COSO I (1992)

Third generation process*

Based on the risk assessment of all business activities;

understand all risks

Determine controls that should be in place to mitigate the risks

No specific scope - determined by previous element

All business risks
COSO II (2004)

Fourth generation process*

${ }^{*}$ Highlighted areas as discussed in the literature on third and fourth generation internal audit engagement process.

audit engagement planning elements are compared with the frameworks provided in the two COSO reports (1992, 2004) in Table 1. Based on this comparison, it could be concluded that the third generation risk-based internal audit engagement process is based on the COSO framework as documented in the 1992 report (or similar frameworks), whereas the fourth generation is based on the COSO framework as documented in the 2004 report (or similar frameworks).

This conclusion was tested on what is occurring in practice or explained in guidance documents. After an Internet search and various research databases, only a few studies and other documentation were unearthed. These are discussed in the next section in the context of either a control-driven (COSO, 1992) or a risk-driven (COSO, 2004) approach to performing internal audit engagements.

\subsection{Research and current practices}

As discussed in Section 1, when referring to risk-based internal auditing, most literature will mention either the role that internal auditing should play in the overall risk management strategy of the organisation, or the internal audit function's annual plan based on the organisation's strategic risks. The literature explains that a risk-based internal audit engagement should consist of five steps, namely: setting the objectives of the audit engagement based on the objectives of the activity under review; identify operational or strategic events within the scope of the audit engagement (including the risks threatening the achievement of the objectives); perform a risk assessment where the risks are measured in terms of the likelihood (the possibility that a given event will occur) and the impact (the result or effect of an event); the risk response (management developing a set of actions to align the risks with the organisation's risk appetite) that management has or must implement; and control activities which should form part of the risk response. However, weaknesses were identified as discussed below.

According to much of the documentation referring to a risk-based approach, when performing an internal audit engagement, only the risk assessment step to identify appropriate controls is incorporated. This indicates that a control-driven approach, as discussed in Section 3.1, is being used (McNamee \& Selim, 1998; Bank of Canada, 1998; Spencer Pickett, 2003, 2006; Deloitte, 2005; Sobel, 2008; Clayton, 2009). Other specific tendencies that should be mentioned include that risk analysis is not performed (McNamee \& Selim, 1998: 103-5; Spencer Pickett, 2003: 402; Clayton, 2009: 35-39); only the controls that mitigate the risks must be included in the audit engagement and no investigation into other mitigating activities (McNamee \& Selim, 1998: 106; Deloitte, 2005: 7); no integration of controls and risk assessment are performed (Spencer Pickett, 2003; Sobel, 2008: 93); internal auditing performs their own risk assessment as part of the audit engagement instead of relying on the formal risk assessment performed by, inter alia, the risk department (Spencer Pickett, 2006: 143-61; Sobel, 2008: 93); and the focus is only on financial risks (Deloitte, 2005: $1-10)$.

Although there is documentation supporting the risk-driven approach (Griffiths, 2006a, 2006b; Pelletier, 2008; Reding et al., 2009), these are either textbooks or guidance documents, or weaknesses that were identified when compared to the processes mentioned in each and the fourth generation risk-based internal audit engagement methodology, namely:

- Internal auditors perform their own risk assessment based on the objectives of the activity under review (Pelletier, 2008: 73-76; Reding et al., 2009: 13-22). If the formal risk management process's risk assessment is used, duplications will be eliminated. However, this will only be possible if the organisation is risk-mature and the risk management process has been audited by the internal audit function and is found to be reliable (De la Rosa, 2008; Baker, 2010: 32).

- Previously, the term risk referred mainly to hazards the possibility that an action has a potentially negative outcome or consequence on reaching the objectives (Prinsloo, 2008: 216-26). The modern approach to risk includes the loss of opportunity - the possibility that an opportunity to achieve something positive could be lost (COSO, 2004: 16). It seems that this concept is still not incorporated into the risk-based internal audit engagement planning (Griffiths, 2006a: 41-42; Pelletier, 2008: 73-76; Reding et al., 2009: 13-22).

- According to the risk management process, the difference between an inherent risk (the possibility of an event occurring that could cause harm to an organisation in the absence of any preventative, corrective or detective measures) and a residual risk (the remaining risk after mitigating activities have been implemented) is the current responses that have been put in place to mitigate the risk to an acceptable level (COSO, 2004: 49-54). The movement between these two levels should thus provide the internal auditors with a starting-point when planning the engagement procedures. However, it seems that this is not currently the case, as most documents suggest focusing on all the high inherent risks (Griffiths, 2006b: 37-40; Pelletier, 2008: 73-76; Reding et al., 2009: 13-22). 
- As mentioned previously, risks cannot be viewed in isolation but must be viewed holistically (COSO, 2004: 15). With reference to an internal audit engagement, this could mean that a risk identified in a specific business unit or process might flow over to another. The internal auditor should review the effect of these risks on the whole instead of the smaller unit only (Griffiths, 2006b: 26-30; Pelletier, 2008: 73-76; Reding et al., 2009: 13-22).

- It seems that controls are mostly investigated as a means of reducing risks. Other risk-mitigating procedures or risk responses, such as sharing the risk, avoiding the risk or accepting the risk (COSO, 2004: 55-66), are not mentioned, but could be more favourable or cost-effective (Griffiths, 2006a: 42; Pelletier, 2008: 73-76; Reding et al., 2009: 13-28).

Apart from the above weaknesses in performing a risk-based approach, the internal audit engagement process used in much of the literature still refers to the control-driven process (COSO, 1992), even though it should be risk-driven $(\mathrm{COSO}, 2004)$ based on the internal audit process generation as reflected in the literature sources and their respective dates (Spencer Pickett, 2003, 2006; Deloitte, 2005; Sobel, 2008; Clayton, 2009).

It seems that although some individuals and organisations are promoting the performance of riskbased internal audit engagements based on the risk management process, and more specifically the process documented in the 2004 COSO Report, there are still a few gaps that prevent the utilisation of the process to its fullest potential. From the above literature review, a risk-based internal audit engagement model was developed, addressing these gaps. This model is discussed in the next section.

\section{DEVELOPMENT OF THE MODEL}

While reflecting on the gaps and weaknesses identified above when referring to a risk-based internal audit engagement, a model was developed to be used in this process. It should be noted that the use of the model is based on certain assumptions, namely:

- the organisation is risk-mature and thus has a comprehensive risk management process in place for both strategic and operational levels;

- the risk management process is being driven by the board and senior management and implemented by a body independent of the internal audit function, such as a risk department;

- the risk management process and its outcomes are properly documented, for example, in a risk register;

- the risk appetite (the amount of risk an organisation is willing to accept in pursuit of value; COSO, 2004: 19) and risk tolerance (an acceptable variation or deviation from the risk appetite to ensure that objectives are achieved; COSO, 2004: 124) levels have been set by senior management and the board or, where applicable, by line-management for operational activities; and

- the risk management process has been audited by the internal audit function and the outcome of the process can be relied upon.

In the development of the model, the steps in the risk management process (COSO, 2004) are linked to the planning phase of an internal audit engagement according to the guidance provided by the Institute of Internal Auditors (2012: 2200-1) formal standards and practice advisories (see Table 2). The potential benefits of using this methodology are consistent with the guidance provided by the Institute of Internal Auditors (2012: 2200-2) on the use of the risk management process in the planning of the internal audit function's annual plan.

Table 2 reflects how the steps in the risk management process can be incorporated into the planning phase of an internal audit engagement and explains how the risk management process can be used to develop the internal audit engagement work programme. The steps of the risk management process have been adapted to develop the model, which is also schematically presented in Figure 1 and explained below.

Firstly (step 1), objectives are set for either the strategic level or the operational levels of the organisation. Assuming that this was performed during the risk management process, internal auditing may rely on the outcome of the process as documented in the risk register and use these objectives as the basis for the internal audit engagement objectives.

Secondly (step 2), the inherent risks that have been identified during the risk management process that are threatening the achievement of these objectives should be considered by the internal auditor. All inherent high risk areas are considered to be included in the engagement planning (refer to numbers 1, 2 and 3 in Figure 1). All hazards and opportunities should be included as potential risks (see also Appendix B).

Thirdly (step 3), the internal auditor may use the assessment of inherent risks as documented in the risk register in terms of the likelihood as well as the impact. All inherent risks should also be considered in a holistic context, thus how risk in areas outside the scope of the engagement could affect this engagement and vice versa. For all inherent risks that are not within the risk appetite boundaries (refer to numbers 1,2 and 3 in Figure 1), the assessment of the residual risk should also be obtained from the risk register. The investigation of controls and other activities that are mitigating the high inherent risks (refer to the list in Table 2) are automatically included in the engagement work programme, either for in-depth inspection to determine the adequacy and the effectiveness (refer to number 2 in Figure 1), or for suggestions to facilitate improvement (refer to numbers 1 and 3 in Figure 1). Low inherent risk areas could be eliminated entirely (refer to number 4 in Figure 1), thus conserving the internal auditor's time and scarce resources and assisting management in reducing costly over-controlling processes (see also Appendix B).

Fourthly (step 4), the internal auditor should align the recommendations of each internal audit finding to the appropriate risk response as well as the residual risk level. These could be made on a timely manner by issuing an interim internal audit report (refer to numbers 1 and 3 in Figure 1). Recommendations could focus on either the lowering of the impact (refer to number 1 in Figure 1) or of the likelihood (refer to number 3 in Figure 1) of a risk when additional procedures are needed to mitigate that risk. Internal auditing should keep track of management's action plans to mitigate the risk as well as the impact of the organisation and ensure that management is aware of it (see also Appendix B).

The above explanation of how the risk management process can be used to perform a fourth generation internal audit engagement based on risk could be an appropriate aid to not only reduce the internal auditor's workload, but also to provide a sharper focus. Especially 
Step Risk management process (performed by management, e.g. risk department)

1 - Objective setting

- Outcome (a list of):

- strategic objectives

- operational objectives

2 - Identification of inherent risks

- Outcome (a list of significant):

- hazards

- opportunities that threaten the reach of objectives

3 - Assessment of risks

- Outcome (for each risk the measure of):

likelihood

- impact for both:

- inherent risk level

- residual risk level

- Risk response

- Outcome (for each risk decide to):
avoid
reduce
share
accept
exploit
terminate activity
integrate above

Use in internal audit engagement planning (for a specific activity under review, e.g. business unit or business process)

- The activity's objectives and related criteria form the foundation of the audit engagement objectives and scope:

- Review the objective-setting process and outcome and, if needed, identify further objectives or only focus on priority objectives (based on audit resources available)

- Set the engagement objectives and scope

- The risks threatening the activity's objectives form the foundation of the engagement planning:

- Consider the risk identification process and all relevant exposures identified according to the process

- While obtaining knowledge of the activity, consider other exposures and risks for both hazards and opportunities threatening the reach of the activity's objectives

- The assessment (likelihood and impact) of both the inherent and residual risks are determined:

- Consider the risk assessment process and use outcome or perform own assessment

- Review inherent risk level, current risk responses in place, and residual risk level for each risk

- Measure inherent and residual risk level in the context of the risk appetite

- Focus more on high level risks (inherent risk exceeding the risk appetite)

- For the engagement programme, include current existing responses where the inherent risk is high but the residual risk is within the risk appetite levels (adequacy)

- Investigate whether these responses are functioning as planned (effectiveness)

- Consider low inherent risk for inclusion in the engagement programme by using professional judgement

- Consider high inherent risk where the residual risk remains high for inclusion in the engagement programme by using professional judgement

- The assessment of each risk is measured in terms of the risk appetite

- Residual risk exceeds the risk appetite and must be further treated by means of an appropriate risk response:

- Consider engagement recommendation in terms of the appropriate risk response

- Include in the follow-up phase of the engagement

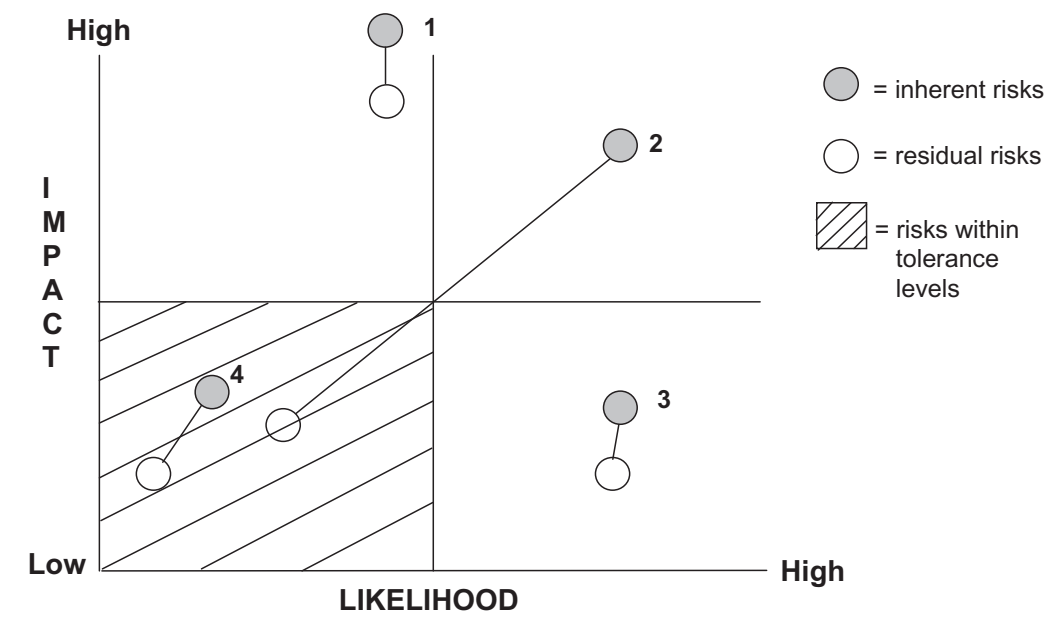

Figure 1: Schematic presentation of risk-based internal audit engagement. 
in the light of the global scarcity of competent internal auditors, the effect of the global economic meltdown on business viability, and the growing complexity of the business environment, to name only a few factors currently affecting the internal audit profession, this could be a tool to ensure more effective and efficient engagements. It is important to note that the professional judgement of the internal auditor should never be compromised and due professional care must be exercised at all times (IIA, 2012: 1200). For example, if the internal auditor suspects a possibility of fraud or if controls seem unnecessary but are also performing a preventative control function for possible collusion, the controls should remain and continue to be included in the engagement work programme.

\section{TEST THE MODEL}

In this section, the testing of the model in a practical situation is described to determine whether the model improves the efficiency and effectiveness of internal audit engagements, as well as obtaining input from chief audit executives on the functionality of the model.

\subsection{Methodology and findings to test the model}

The efficiency and effectiveness of the model was tested by means of a case study provided by a risk-mature company, selected on the basis of its willingness to participate. Before finalising the selection of the company, the assumptions contained in Section 4 had to be applicable.

According to Yin (2003: 2-4), a case study approach allows the researcher to gain an understanding of the holistic and unique characteristics of a given real-life event. The planning phase of an internal audit engagement that had previously been performed by the company's internal audit function was re-evaluated using the risk-based internal audit model. The criteria used when choosing the engagement ranged from the engagement being performed on a high strategic risk area, to being an assurance engagement (as opposed to being a consulting engagement). The engagement had to have been performed previously by the organisation without having the input of the operational risk management process. Finally, the engagement still had to be relevant and had to have been performed recently, preferably in the current or the immediately previous financial year.

Yin (2003: 39-46) demonstrates that a single case study can be used when a theory is being tested. In this case the existing theory was tested against our risk-based internal audit engagement model. The internal audit engagement planning, more specifically the engagement work programme, with its detailed engagement procedures, was re-performed; thus a new engagement plan was developed based on the model. The original engagement work programme and detailed engagement procedures were compared with the ones drawn up using the risk-based internal audit model. Possible differences, advantages, disadvantages, improvements and weaknesses were identified.

After all of the above criteria had been addressed and the relevant information and documentation which were gathered and documented during the execution of the engagement (e.g., the working paper file) had been obtained, the execution of the case study was planned:
- A clear understanding of the system description was obtained.

- The audit procedures performed during the engagement were listed.

- The audit findings were examined and summarised.

- The current risk register for the operational area was obtained. The risks identified in the risk register were classified as high/moderate inherent risk areas that had lower residual risk levels after controls were implemented (refer to number 2 in Figure 1); low inherent risk areas (refer to number 4 in Figure 1); and high/moderate inherent risk areas that remained at high residual risk after controls were implemented (refer to numbers 1 and 3 in Figure 1). The risk register was used as the basis on which to decide whether or not engagement procedures should be included in the engagement programme.

- The risks and controls in the risk register were used as the basis to re-perform the engagement.

The following criteria were used to determine how the inherent risks and the controls recorded in the risk register should be included in the audit engagement's list of engagement procedures (movement of inherent risks to residual risks):

- controls for high/moderate inherent risk areas that had lower risk levels after controls were implemented should be included in the audit engagement programme (refer to number 2 in Figure 1);

- controls for low inherent risk areas should not be included in the audit engagement programme (refer to number 4 in Figure 1);

- controls for high/moderate inherent risk areas that remained at a high risk level should not be included in the audit programme but be reported to management, for example an audit finding in the audit report (refer to numbers 1 and 3 in Figure 1);

- the above list of engagement procedures was compared to the original list of engagement procedures to determine whether fewer tests would have been performed if the risk-based model had been used; and

- the list of engagement findings was compared to the original engagement findings, as listed in the audit report, to determine whether all the relevant audit findings would have been discovered had fewer tests been performed.

The results of the case study are summarised in Table 3 (see also Appendix B). In the first column the processes of the activity that was audited are numbered as per the audit programme. In the second column the number of risks, as listed in the risk register, applicable to each process area is listed. The word 'General' in the first column refers to a risk that is applicable to all the areas. In the third column the difference between the inherent risk and the residual risk indicates whether the movement warrants an inclusion in the audit programme proposed by the model. In the fourth column, 'Influence on audit procedures performed', the table differentiates between the various procedures currently included (walk-through tests were mainly used and these are excluded from the analysis), the procedures included if the risk-based audit model had been used, and the net effect on the audit programme. In the fifth column, on audit findings, the results as to whether findings would have been identified when performing only the audit procedures as proposed in the risk-based audit model are investigated. The sixth column addresses the possible inclusion of further audit findings 
Table 3: Summary of results of the case study

\begin{tabular}{|c|c|c|c|c|c|c|c|c|c|c|}
\hline \multirow[t]{2}{*}{$\begin{array}{l}\text { Process } \\
\text { area }\end{array}$} & \multirow{2}{*}{$\begin{array}{l}\text { Number of } \\
\text { risks as per } \\
\text { risk register }\end{array}$} & \multirow{2}{*}{$\begin{array}{c}\text { Risks with } \\
\text { movement that } \\
\text { indicates } \\
\text { inclusion }\end{array}$} & \multicolumn{3}{|c|}{$\begin{array}{c}\text { Influence on audit } \\
\text { procedures performed }\end{array}$} & \multicolumn{2}{|c|}{ Audit findings } & \multicolumn{3}{|c|}{$\begin{array}{l}\text { Additional finding } \\
\text { or discussion }\end{array}$} \\
\hline & & & $\begin{array}{l}\text { Currently } \\
\text { included }\end{array}$ & $\begin{array}{l}\text { After use } \\
\text { of model }\end{array}$ & $\begin{array}{l}\text { Nett } \\
\text { effect }\end{array}$ & $\begin{array}{l}\text { Currently } \\
\text { included }\end{array}$ & $\begin{array}{l}\text { Use of } \\
\text { model }\end{array}$ & $\begin{array}{l}\text { Over } \\
\text { control }\end{array}$ & $\begin{array}{l}\text { Weak } \\
\text { controls }\end{array}$ & Othert \\
\hline 1 & 4 & 2 & 4 & 2 & Fewer & None & $\mathrm{N} / \mathrm{A}$ & & 2 & \\
\hline 2 & 6 & 3 & 5 & 3 & Fewer & Finding 1 & Yes & & 2 & \\
\hline 3 & 4 & 2 & 4 & 2 & Fewer & None & $\mathrm{N} / \mathrm{A}$ & & 2 & \\
\hline 4 & 5 & 1 & 4 & 1 & Fewer & None & $\mathrm{N} / \mathrm{A}$ & & 4 & \\
\hline 5 & 6 & 3 & 3 & 3 & Same & None & $\mathrm{N} / \mathrm{A}$ & & 1 & 1 \\
\hline 6 & 2 & 2 & 2 & 2 & Same & None & $\mathrm{N} / \mathrm{A}$ & & & \\
\hline \multirow[t]{4}{*}{7} & 4 & 2 & 4 & 2 & Fewer & & & 1 & 2 & \\
\hline & & & & & & Finding 2 & Yes & & & \\
\hline & & & & & & Finding $3^{*}$ & Yes & & & \\
\hline & & & & & & Finding 4 & Yes & & & \\
\hline \multirow[t]{3}{*}{ General } & 10 & 4 & 0 & 4 & More & & & 1 & 1 & 4 \\
\hline & & & & & & Finding 5 & Yes & & & \\
\hline & & & & & & Finding 5 & Yes & & & \\
\hline
\end{tabular}

*Finding 3 was not accepted by management as it is too difficult to implement a solution.

**`Other findings' refers to risks that are high and should be brought to management's attention in order that they may be addressed accordingly.

and/or the need for discussions with management. The overall results of the case study indicate that if the model had been used, fewer audit procedures would have been performed (more efficient) but that all the audit findings would still have been included in the audit report (effective).

The process area 'General' refers mainly to strategictype risks that reflect on all the other process areas and were not included in the initial audit scope. However, if these had been included, the value that internal auditing could add rises even further. Furthermore, for this specific case study, additional audit findings could have been made, including areas where weak controls exist, areas subject to over-controlling, and other more strategic weaknesses or problems that need to be brought to management's attention.

\subsection{Methodology and findings from interviews}

Formal interviews were conducted with five chief audit executives employed by Top 40 private sector companies that were listed on the JSE Limited on 8 April 2009. The companies were chosen based on their level of risk maturity as well as the risk maturity level of the internal audit functions. The risk maturity levels of the 40 companies were determined using the Risk and Insurance Management Society (RIMS, 2006) maturity model. The five companies with the highest levels of overall risk maturity were chosen, considering that the internal audit function's maturity level also had to be high. The reasoning behind this decision was that risk management is a relatively new concept, and if the internal audit function is addressing this concept in all or most of their activities (referring to risk maturity), there is a greater than even probability that internal auditors will follow a risk-based approach when performing internal audit engagements. Although a structured questionnaire (see Appendix A) was developed, the method that was used to gather the desired information was a 'descriptive method survey research', from which the quantitative primary data was obtained. This data was collected by means of personal interviews and the data consists of facts, opinions, beliefs, attitudes and behaviours (Mouton, 2001: 152-53; Saunders, Lewis \& Thornhill, 2007: 310).
Advantages linked to this type of data gathering include (Saunders et al., 2007: 354-60) a high level of confidence that the right person has responded; the likelihood of contamination of the respondent's answers is low; open and closed questions can be included; and the respondent's participation is enhanced by this face-to-face interaction.

Input was obtained from the chief audit executives on the current practices performed, the overall benefits of using the model during the performance of an internal audit engagement, as well as on specifics, such as whether low inherent risk areas should be included in the engagement planning, how risks should be treated where both the inherent and residual risks are above the risk appetite, and other general comments (see also Appendix B).

Results indicated that although the respondents were under the impression that they were following the COSO 2004 methodology, the fear of not covering all the required aspects of the engagement, and of being 'caught out' by management should they not identify all the relevant weaknesses, as well as other unique problems, was the motivation for still following the more comprehensive, but resource-hungry COSO 1992 audit methodology.

The second significant result was that internal auditors still tend to perform their own risk assessment instead of relying on the risk management process. If internal auditing has provided assurance on the risk management process, then there should be no reason not to trust the risk management process's outcome for the identification, assessment and mitigating activities as documented in the risk register. If the engagement reveals otherwise, this information should be used to update the risk register.

The third significant result was that some organisations have not fully developed their integrated risk management processes. This then makes it difficult for the internal auditor to bring risk that is technically outside the audit scope into the engagement, or to bring into the audit engagement risks identified during the engagement that have an effect on another area. This widened riskincorporation process can only be fully implemented by the internal audit function when the risk department is focused on the integration of organisation-wide risk 
management. Until such time, the internal auditor should be aware of the weakness in the methodology and, where applicable, refer to risks outside the scope of the audit, or to incorporate risks identified in this engagement into a later engagement.

The fourth significant finding confirmed that internal auditors are justifiably known as control experts and are used to providing recommendations on controls. However, sometimes it is more effective and efficient to suggest another form of risk mitigation, such as sharing the risk between business sections or entities, or eliminating the activity that gives rise to a specific risk. Internal auditors therefore should also consider the negative effects of over-controlling, as unnecessary controls are costly to any organisation. Results indicated that this was still far from their default position.

The fifth result of the empirical study indicated that low risks should not be included in the internal audit engagement, not even on a surprise basis. Thus, if the risk management process can be relied upon, low inherent risks should be eliminated from the engagement scope. However, it is suggested that the internal auditor should always use professional judgement when making this decision, as some low-risk areas could lead to other risks arising, such as fraudulent activities.

The sixth key result indicated that high inherent risks should only be included in the engagement planning once control adequacy has been investigated, that is, once the extent to which the control reduces the risk has been established. Only those controls that do add to the risk mitigation should be investigated for the effectiveness of the control - the extent to which the control is implemented and properly carried out.

The final result showed that if the risk-based internal audit model is used correctly for the performance of an internal audit engagement, more audit findings are likely to be revealed than with conventional audits. These could include formal findings that should be reported in the audit report, aspects of the business that should be brought to management's attention for a decision on whether each should be addressed or not, and finally, preparing and presenting an informal finding that is not included in the final audit report, for discussion and ad hoc attention.

\section{CONCLUSION AND RECOMMENDATIONS}

The objective of the study was to provide a model that will improve the efficiency and effectiveness of internal audit engagements by optimally implementing a risk-based approach. To reach this objective, the internal audit engagement process was investigated to determine how risk methodologies can be included. A model was developed by using the risk management process as documented in the 2004 COSO Report. Thereafter it was tested in a practical situation as well as by obtaining the input from chief audit executives of prominent South African companies.

As the term 'risk-based internal auditing' is relatively new, it seems that the terminology is not used consistently: it is used interchangeably to describe the audit of the risk management process, planning the internal audit function's annual activities based on risk, or performing an internal audit engagement based on risks. When considering the overall evolution of the internal audit engagement process, it seems that 'risk' has only been incorporated into the process since the 1990s. However, it is only since the beginning of the new millennium (2000s) that the risk management process has been used as a foundation for the planning phase. Even then, all the elements of the risk management process have not yet been fully implemented and further improvements to streamline the internal audit engagement process are needed.

During the testing of the risk-based internal audit engagement model, the planning phase of an internal audit engagement that had been performed previously was re-performed using the model's methodology. The results indicate that if the model had been used in executing the engagement, fewer audit procedures would have been performed, but at the same time more audit findings would have been uncovered, thus demonstrating that the risk-based internal audit model for assurance engagements will ensure that audits are performed more effectively and efficiently.

The chief audit executives interviewed all agreed that implementing the model would certainly benefit the internal audit function overall, but more specifically the internal audit assurance engagement, especially as internal auditors tend to protect themselves by overauditing. Valuable internal audit resources should not be wasted on areas that are not effectively controlled by management: these should rather be speedily brought to management's attention. Thus, audit engagements can and should be more focused. However, respondents were concerned that risk management systems are not yet mature enough to accommodate the model. A summary of the model, input obtained form chief audit executives and the results of the case study are summarised in Appendix B.

Areas for further research include the expansion of the input obtained from chief audit executives to other stakeholders, such as the audit committee, management and the risk identification and control bodies, on the performance of risk-based internal auditing. Also, the investigation of the state of maturity of the risk management process for operational areas, to ensure that risks are holistically addressed, are clustered according to a business unit and/or a business process, and that the process outcome is properly documented. The latter should enable internal auditing to implement an effective and efficient risk-based approach to their activities, including the performance of a fully risk-based internal audit engagement.

\section{REFERENCES}

Baker, N. (2010), 'Equipped for governance', Internal Auditor, Vol. 67, No. 1, pp. 29-32.

Bank of Canada (1998), Risk-based internal auditing and dynamic control assessment: revolutionising internal audit services, Altamonte Springs, FL: Institute of Internal Auditors.

Castanheira, N., Rodrigues, L. L. \& Craig, R. (2010), 'Factors associated with the adoption of risk-based internal auditing', Managerial Auditing Journal, Vol. 25, No. 1, pp. 79-98.

Clayton, D. (2009), 'A risk-centric approach that works', Internal Auditor, Vol. 66, No. 1, pp. 35-39.

Committee of Sponsoring Organisations of the Treadway Commission (COSO) (1992), Internal control - integrated framework: framework, Jersey City, NJ: Sponsoring Organisations of the Treadway Commission.

Committee of Sponsoring Organisations of the Treadway Commission (COSO) (2004), Enterprise risk management 
integrated framework: executive summary, Jersey City, NJ: Sponsoring Organisations of the Treadway Commission.

Committee of Sponsoring Organisations of the Treadway Commission (COSO) (2012), COSO develops draft update to internal control - integrated framework and related supporting documents. Available at: http:/ / www.coso.org (accessed 21 August 2012).

De la Rosa, S. 2008. How to effectively review your organisation's risk management process. Institute of Internal Auditors South Africa Training Programme, Johannesburg.

Deloitte (2005), Lean and balanced: how to cut costs without compromising compliance. Available at: http://www. deloitte.com/dt/research/0,1015,\%20Sid\%253D7108\% 2526cid\%253D158271,00.html (accessed 17 April 2008).

Finance, Accounting, Management Consulting and other Financial Services (Fasset) Sector Education \& Training Authority (SETA) (2011), Fasset Scarce Skills 'Guideline: February 2011'. Available at: http://www.fasset.org.za/ down-loads-/research/SS_Guide-_2011_V4.pdf (accessed 26 July 2011).

Gendron, Y., Cooper, D. J. \& Townley, B. (2007), 'The construction of auditing expertise in measuring government performance', Accounting, Organisations and Society, Vol. 32, No. 1-2, pp. 105-33.

Gramling, A. A., Maletta, M. J., Schneider, A. \& Church, B. K. (2004), 'The role of the internal audit function in corporate governance: a synthesis of the extant internal auditing literature and directions for future research', Journal of Accounting Literature, Vol. 23, pp. 192-244.

Griffiths, D. (2006a), 'Risk-based internal auditing: an introduction', 15/03/2006, Version 2.0.3. Available at: http:// www.internalaudit.biz/supporting-pages/resources.htm (accessed 20 February 2008).

Griffiths, D. (2006b), 'Risk-based internal auditing: three views on implementation', 15/03/2006, Version 1.0.1. Available at: http://www.internalaudit.biz/supporting-pages / resources.htm (accessed 20 February 2008).

Hull, J. C. (2009), 'The credit crunch of 2007: what went wrong? Why? What lessons can be learned?', The Journal of Credit Risk, Vol. 5, No. 2, pp. 3-18.

Hyde, G. (2007), 'Enhanced audit testing', Internal Auditor, Vol. 64, No. 4, pp. 65-68.

Institute of Directors (IOD) (2009), King report on governance for South Africa, King Committee on Corporate Governance, Johannesburg.

Institute of Internal Auditors (IIA) (2012), International Professional Practices Framework. Available at: https://na. theiia.org/standards-guidance/recommended-guidance/ pages/newly released (accessed 11 April 2012).

Keen, S. (2008), Economics 101 - what the global meltdown means. Available at: http://www.theage.com.au?action/ printArtile?id=226496 (accessed 12 February 2009).

Khanna, V. K. (2011), 'A survey-based assessment of progress in the implementation of risk-based internal audit in Indian banks', The IUP Journal of Accounting Research $\mathcal{E}$ Audit Practices, Vol. 10, No. 4, pp. 53-96.

Koutoupis, A. G. \& Tsamis, A. (2009), 'Risk-based internal auditing within Greek banks: a case study approach', Journal of Management and Governance, Vol. 13, No. 1-2, pp. 101-30.

Lam, J. (2009), 'Key requirements for enterprise-wide risk management: lessons learned from the global financial crisis', RMA Journal, Vol. 91, No. 8, pp. 22-27.

Lubbe, D. (2009),' "Politieke bedrog" dalk "n rede vir ekonomiese krisis", Volksblad. Available at: http:/ /jv.news24.com/Die _Volks-blad/Nuus/0,583\%20_2533291,00.html (accessed 20 August 2009).
Mathker, V. (2008), 'Sub-prime bomb: where were the auditors?' Available at: http://in.rediff.com/cms/print.jsp?docpath $=/ /$ money $/ 2008 / 0 c t / 15 b c r i s i s . h t m$ (accessed 24 March 2009).

McNamee, D. \& Selim, G. M. (1998), Risk management: changing the internal auditor's paradigm, Altamonte Springs, FL: Institute of Internal Auditors.

Mouton, J. (2001), How to Succeed in your Master's E Doctoral Studies: a South African Guide and Resource Book, Pretoria: Van Schaik.

Olah, A. J. (2009), 'Where was ERM?', Internal Auditor, Vol. 66, No. 1, p. 11.

Pelletier, J. (2008), 'Adding risk back into the audit process', Internal Auditor, Vol. 65, No. 4, pp. 73-76.

PricewaterhouseCoopers (2008), Internal audit 2012: a study examining the future of internal auditing and the potential decline of a controls-centric approach. Available at: http:// www.pwc.com/images/gx/eng/about/svcs/grms/PwC _IAS_2012.pdf (accessed 3 May 2008).

Prinsloo, J. (2008), 'The development and evaluation of risk-based approaches'. Unpublished MCom (Accounting) dissertation, University of the Free State.

Reding, K. F., Sobel, P. J., Anderson, U. L., Head, M. J., Ramamoorti, S., Salamasick, M. \& Riddel, C. (2009), Internal Auditing: Assurance and Consulting Services, 2nd edn, Altamonte Springs, FL: Institute of Internal Auditors Research Foundation.

Risk and Insurance Management Society (RIMS) Inc. (2006), RIMS risk maturity model for enterprise risk management. Available at: http://www.rims.org/rmm (accessed 12 March 2008).

Saunders, M., Lewis, P. \& Thornhill, A. (2007), Research Methods for Business Students, 4th edn, Harlow: Prentice Hall.

Sobel, P. (2008), 'Risk management-based auditing', Internal Auditor, Vol. 65, No. 4, pp. 92-93.

Spencer Pickett, K.H. (2003), The Internal Auditing Handbook, 2nd edn, Hoboken, NJ: John Wiley \& Sons.

Spencer Pickett, K.H. (2006), Audit Planning: A Risk-Based Approach, Hoboken, NJ: John Wiley \& Sons.

Spira, L. F. \& Page, M. (2003), 'Risk management: the reinvention of internal control and the changing role of internal audit', Accounting, Auditing $\mathcal{E}$ Accountability Journal, Vol. 16, No. 4, pp. 640-61.

Yin, R. K. (2003), Case Study Research: Design and Methods, 3rd edn, London: Sage Publications.

\section{AUTHOR PROFILES}

Philna Coetzee is a Professor in internal auditing at the Department of Auditing, University of Pretoria. She is also the Coordinator of the Centre of Internal Audit Excellence programme of the Institute of Internal Auditors Inc. She has published widely on the topic of auditing and internal auditing.

Dave Lubbe is a Professor at the Centre for Accounting at the University of the Free State. He has guided many students to their PhD and Master's degrees in the fields of auditing and governance. He also holds a law degree, has written and published poems and lyrics, and regularly writes for newspapers and magazines on a variety of pertinent topics. 


\section{APPENDIX A}

\section{Structured interview schedule: Private sector}

1 Organisational background*

2 IIA Standards*

3 The changing internal audit environment*

4 The risk management framework*

5 Risk management process*

6 Annual planning of the internal audit function's activities*

7 Risk-based internal audit assurance engagements

7.1 When conducting the engagement planning, do you incorporate risk into the internal audit process by using the following? (Explain if necessary):

COSO I model terminology

COSO II model terminology

Yes $\quad$ No

No Not sure

If another methodology is used, indicate:

Yes $\quad$ No

Not sure

7.2 If using the COSO II model, how is the following information obtained? Information Use auditee input

Use risk management process results (risk register) No/limited information
(internal auditor has to obtain)
Other (provide details)

Operational (auditee) objective setting

Risk identification for inherent risks

Risk assessment (measure)

for inherent risks

Current risk mitigation

activities

Risk assessment (measure)

for residual risks

7.3 When planning the internal audit engagement, which one (or more) of the following strategies is used as a starting point?

Previous year's working Inherent risks as per paper file the risk register

Difference between the inherent and residual risk as per the risk register

Other

7.4 When planning the internal audit engagement, which of the following are included?

Both threats and loss of opportunities are investigated as possible risks

The effect that a risk(s) may have on another area (outside the scope of the engagement) is considered
The effect that a risk(s) in another area (outside the scope of the engagement) may have on this engagement is considered
Recommending activities other than controls to mitigate risk to an acceptable level is considered

7.5 Please describe any further aspect relevant to your organisation's internal audit engagement planning methodologies based on risk that was not covered in this questionnaire:

8 Risk-based internal audit assurance engagement model (Explain the model - see Figure 1 - to the interviewee)

8.1 Do you think the model can be used when performing your internal audit assurance engagement? Yes No Reasons:

8.2 Do you think the model will reduce the extent of engagement procedures to be performed?
Yes
No
Reasons:

8.3 Do you think the model will be effective in focusing on the crucial aspects? Yes No Reasons:

8.4 Do you think the model will be efficient (e.g., save time) whilst still being effective? Yes No
Reasons:

8.5 Do you think the model will assist in the following:

$\begin{array}{llll}\text { Eliminating ineffective controls } & \text { Yes } & \text { No } & \text { Reason: } \\ \text { Eliminating unnecessary controls } & \text { Yes } & \text { No } & \text { Reason: } \\ \text { Eliminating redundant controls } & \text { Yes } & \text { No } & \text { Reason: } \\ \text { Eliminating excessive controls } & \text { Yes } & \text { No } & \text { Reason: } \\ \text { Simplifying complex controls } & \text { Yes } & \text { No } & \text { Reason: }\end{array}$

8.6 Do you think low inherent risks should be included in the audit planning?
Full inclusion
Only partial (judgement)
Only on surprise basis
No inclusion

Provide reasons:

8.7 Do you think a high inherent risk with a residual risk above the risk appetite should be included in the planning of audit procedures?

$\begin{array}{ccc}\begin{array}{c}\text { Must be included in full } \\ \text { (audit all controls) }\end{array} & \begin{array}{c}\text { Only focus on adequacy } \\ \text { of controls }\end{array} & \begin{array}{c}\text { Only focus on effectiveness } \\ \text { of controls }\end{array}\end{array}$ Provide reasons:

8.8 Please provide any further comments that may be used to refine the model:

8.9 May the model be tested at your organisation against a prior engagement?

* Detailed questions not included as it does not form part of the scope of this article. 


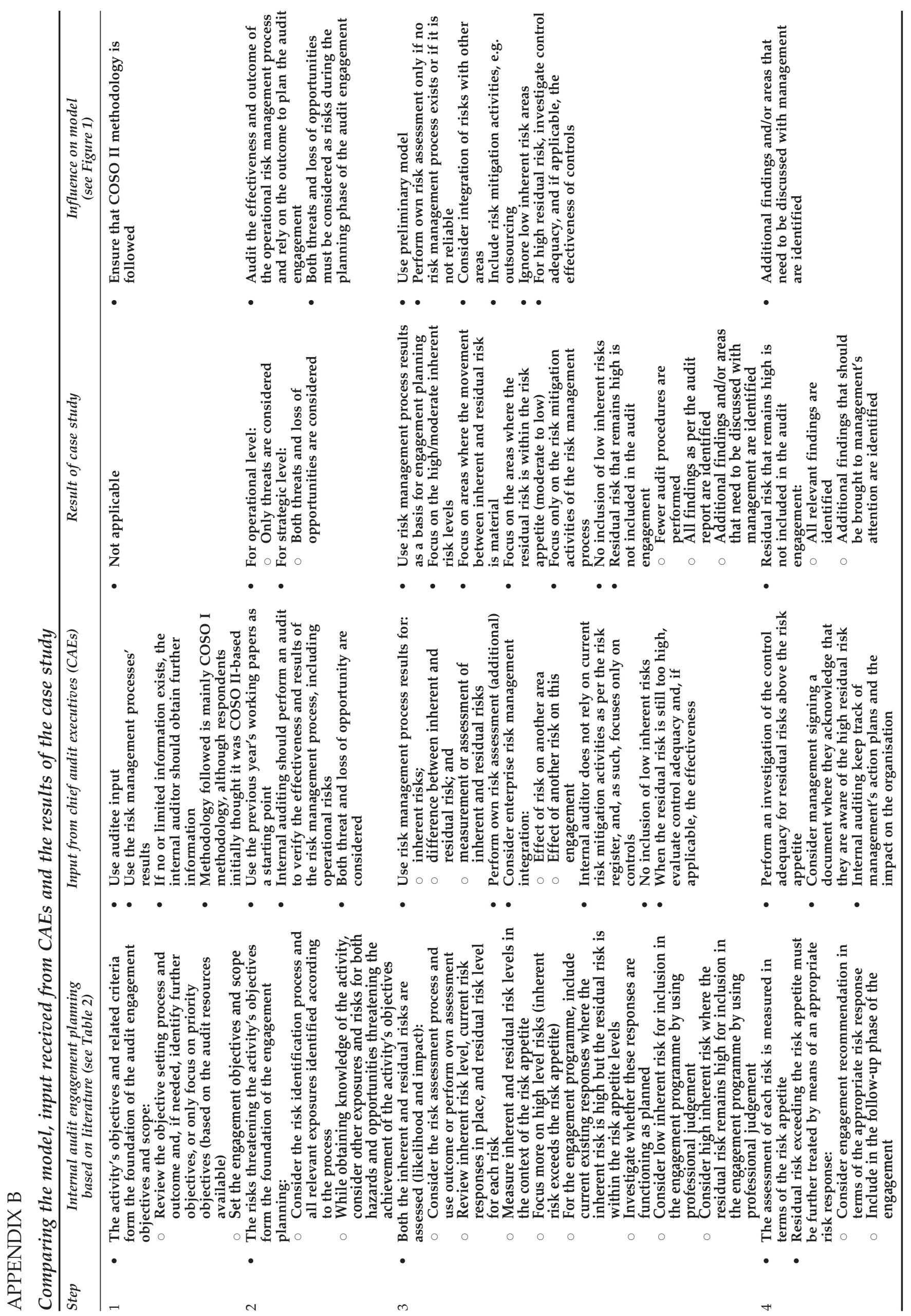

